\title{
On-trial and intertrial responding in eyelid conditioning as a function of US-intensity, percentage reinforcement, and the similarity between the CS and intertrial stimulus'
}

\author{
John W. Moore and Frederick L. Newman \\ UNIVERSITY OF MASSACHUSETTS
}

\begin{abstract}
192 human Ss received 96 conditioning trials in a factorial experiment which combined two levels of USintensity, two percentages of reinforcement, and two levels of similarity between the CS and the intertrial stimulus (ITS). Percentage CRs was an increasing function of US-intensity and percentage reinforcement and a decreasing function of CS-ITS similarity, but the effects of these variables on intertrial responding were negligible.
\end{abstract}

\section{Problem}

The purpose of this experiment was to determine for eyelid conditioning the function relating intertrial responding (ITR) to variations of (a) US-intensity, (b) percentage reinforcement, and (c) the similarity between the CS and the intertrial stimulus (ITS). Selection of the independent variables of this experiment was based upon expectations that they particularly should affect ITR. It was expected that the effect of making the two stimuli more similar would be to (a) decrease conditioned responding because of greater generalized inhibition from the ITS and (b) increase ITR because of greater generalized excitation from the CS to the ITS. Both US-intensity and percentage reinforcement should affect the nature of these generalization processes by their contribution to the "habit" or associative component of performance. In addition, insofar as blink rate is correlated with "arousal" or drive, US-intensity and percentage reinforcement should affect ITR by their contributions to any nonassociative components of performance.

\section{Method}

The gross features of the apparatus, particularly the Ss' room, were identical to the two chair arrangement described by Moore \& Gormezano (1961). The recording and stimulating equipment differed in the following respects: The CS consisted of sinusoidal tones generated by two Hewlett Packard Model 200 ABR audio-oscillators and were delivered over loud speakers inside S's enclosure. The parameters of recording eyelid movements were as follows: The response transducers were Giannini minitorque potentiometers (model 35153, $10 \mathrm{~K} \Omega$, Type 2 wiring) activated by \pm 15 vdc with respect to the wiper. Signals from this arrangement were recorded by an Offner two-channel ink-writing Dynagraph (Type RP with no pre-amplification stage and attenuation of power amplifiers set at $500 \mathrm{mv} / \mathrm{cm}$ ).

The Ss were 238 University of Massachusetts undergraduates conscripted from Introductory Psychology classes. Data from 192 of these were used in the analyses of results. Of the remaining $44 \mathrm{Ss}, 40$ were discarded because their ITR record was considered unreadable (see below).

Each $\mathrm{S}$ was randomly assigned to one of all possible combinations of two intensity-levels of an airpuff-US (40 or $160 \mathrm{~mm} \mathrm{Hg}$ static pressure in a 1/4-in manometer), two reinforcement schedules $(100 \%$ or $50 \%$ "random"), and two levels of similarity between the CS and ITS (CS-ITS similarity). Low similarity was obtained by using, e. g., an $800 \mathrm{cps}$ tone, $60 \mathrm{db}$ SPL, as the CS and a $720 \mathrm{cps}, 60 \mathrm{db}$ SPL, during the intertrial interval. High similarity was achieved by setting both audio-oscillators at $800 \mathrm{cps}, 60 \mathrm{db}$ SPL. Due to residual differences between the two oscillators and due to the fact that the offset of one tone occurred simultaneously with the onset of the other, this procedure produced a CS which was highly similar to and yet perfectly distinguishable from the ITS. Additional orthogonal variables were S's sex, the two enclosure-recording channels, and whether on audiooscillator produced the CS and the other the ITS, or vice versa. The result was a $2^{6}$ factorial design with three experimental variables and three control variables $(\mathrm{N}=3 /$ cell $)$.

All Ss received 96 acquisition trials with ITIs of 20 , 25 , and $30 \mathrm{sec}$, randomly distributed. The CS-US interval was $.5 \mathrm{sec}$. and the CS terminated together with the $100 \mathrm{msec}$. US. Ss received "neutral" instructions over an intercom immediately before the first trial, and no "ready" signals were used.

Conditioned responses were defined as any positive deflection of the recording pen of at least one $\mathrm{mm}$ starting in the interval from 150 to $525 \mathrm{msec}$. after CS-onset. An intertrial response was defined as a "clear blink" as distinguishable from relatively long lasting shifts in the recording baseline such as would be produced by prolonged eye closure. Data from Ss whose intertrial records indicated long periods of recurrent eye closure were discarded from the analysis. The decision to discard was strictly independent of the 
Table 1. Mean Percentage CRs, Mean Rate of ITR and, Number of Discarded Subjects as a Function of US-Intensity, Percentage Reinforcement and Similarity Between the CS and ITS

Similarity Between CS and ITS

\begin{tabular}{crccc} 
US-Intensity & \multicolumn{1}{c}{$\%$} & & High \\
& Reinf. & Rate of & Discarded \\
& & ITR & Ss \\
High & 50 & 49.3 & 14.0 & 4 \\
(160 mm Hg) & 100 & 74.4 & 13.7 & 4 \\
Low & 50 & 40.8 & 11.9 & 8 \\
(40 mm Hg) & 100 & 50.1 & 13.2 & 6
\end{tabular}

experimental conditions under which $\mathrm{S}$ had been run. Table 1 indicates the distribution of discarded Ss among experimental conditions.

\section{Results}

The means of percentage CSs for each experimental group, averaged over the 96 trials of the experiment, appear in Table 1. All statistical analyses were performed upon the arcsine transformations of individual percentage-scores. The mean percentage CRs were (a) 66.5 and 52.0 under high and low US-intensity, respectively, $F(1,128)=16.75)$; (b) 65.9 and 52.5 under 100 and $50 \%$ reinforcement, respectively, $\mathrm{F}(1,128)=18.58$; and (c) 64.8 and 53.7 for high low similarity between the CS and ITS, respectively, $\mathrm{F}(1,128)=8.29$.

The rate of ITR for a given ITI was computed by counting the number of .5 -sec. unit-intervals containing a response and then dividing by the total number of 5-sec. units within the ITI. Mean rates of ITR, averaged over the 95 ITIs of the experiment, appear in Table 1. The only significant effect obtained from analysis of variance on the arcsine transforms of ITR scores was the second order interaction produced by higher mean rates of ITR under high CS-ITS similarity than under low similarity in all combinations of US-intensity and percentage reinforcement with the pronounced exception of the combination of low US-intensity and $50 \%$ reinforcement, $\mathrm{F}(1,128)=4.15$.

\section{Discussion}

As predicted from the hypothesis that stimulus generalization occurs between the CS and ITS, low CS-ITS similarity produced higher CR-performance than did high similarity. While $\mathrm{Ss}$ in the high similarity group might merely have had difficulty detecting the CS under the extreme conditions in which the two audio-oscillators were nominally producing "identical" tones, the rate of ITR was higher under high similarity than under low similarity in the three out of four comparisons.
The effects of percentage reinforcement and US-intensity upon CR-performance in this experiment was a conventional result. However, it was expected that increases in the value of both variables would increase ITR through their effect on "arousal" or drive. There was little solid evidence to support this expectation.

The general importance of recording ITR at all would seem to be mixed. There can be little doubt that information of this sort is valuable in so far as it can provide additional criteria by which to test the predictions of various hypotheses; generalization between on-trial and intertrial stimuli, for example. On the other hand, a measure of ITR is of doubtful value as a covariate which must be taken into account in order to arrive at valid conclusions about eyelid conditioning. The present experiment adds to the growing evidence (Mattson \& Moore, 1964; Perry \& Moore, 1964) that the effects of a wide class of independent variables upon ITR are negligible compared with their effects upon performance.

\section{References}

MATTSON, M., \& MOORE, J. W. Intertrial responding and CS-intensity in classical eyelid conditioning. J.exp. Psychol., 1964, in press.

MOORE, J. W., \& GORMEZANO, I. Yoked Comparisons of instrumental and classical eyelid conditioning. J. exp. Psychol., 1961, 62, 552-559.

PERRY, S. L., \& MOORE, J. W. The partial reinforcement effect sustained through blocks of continuous reinforcement in classical eyelid conditioning J. exp. Psychol., 1964, in press.

\section{Note}

1. The investigation was supported in part by Public Health Service Grant NIH-HD-00955-01. The authors wish to acknowledge the assistance of Philip Tolin and Jean Pezzoli who participated under the undergraduate work-scholarship program of the University of Massachusetts. 